\title{
Atmospheric water infiltration intensity in non-rainfall periods under conditions of varied soil moisture
}

\author{
Matgorzata Dawid and Grzegorz Janik \\ Institute of Environmental Protection and Development, Wrocław University of Environmental and Life Sciences, \\ pl. Grunwaldzki 24, 50-363 Wrocław, Poland
}

Received July 26, 2017; accepted February 21, 2018

\begin{abstract}
The paper presents a function-type relation which demonstrates that volumetric moisture of the surface horizon of soil has an effect on the intensity of atmospheric water infiltration during non-rainfall periods. The relation, developed and then verified on the basis of independent material, reveals that the intensity of infiltration decreases with an increase in volumetric moisture of soil. For the case presented herein, infiltration ceases when volumetric moisture is higher than $0.15 \mathrm{~m}^{3} \mathrm{~m}^{-3}$. The developed function also takes into account the effect of atmospheric conditions through the introduction of another argument into the domain. The aforementioned is in the form of potential condensation efficiency measured on a dew collector, and assumes the form of a modified logistic function.

Keyw ords: volumetric moisture of surface layer of soil, infiltration in non-rainfall periods, potential condensation efficiency
\end{abstract}

\section{INTRODUCTION}

In non-rainfall periods, soil is also supplied with water from the atmosphere (Jacobson et al., 2015; Kidron et al., 2014; McHugh et al., 2015; Tomaszkiewicz et al., 2015). This is an effect that comes about due to the formation of dew, hoarfrost, soil-water vapour condensation and atmospheric water adsorption (Alishaev, 2013; Janik et al., 2014; Zhang et al., 2015). The importance of these processes in the water balance of the soil surface layer is demonstrated not only in arid (desert) areas, but also in humid regions (Cassity-Duffey and Cabrera, 2016). Infiltration in nonrainfall periods is defined as being the water flux from the atmosphere through the plane of soil surface (further on in the paper it is denoted with the symbol $E^{R}$ ). It is a physical process that comes into play at the boundary of two media (Beysens, 2006; Jacobs et al., 2000), hence, its intensity is dependent on a number of elements determining the status and physical properties of both the atmosphere and the soil (Fig. 1). Furthermore, it depends directly on the intensity of water condensation on soil surface and on the soil capacity for water absorption. The most important element of the state of the atmosphere that affects the intensity of water condensation is the relative humidity of the air close to soil surface $(R H)$ (Kaseke et al., 2012a; Komori and Kim, 2016; Maphangwa et al., 2012). This is a measure of water vapour availability that depends on such factors as e.g. wind direction and velocity (Beysens et al., 2005; Bryś, 2013; Malek, 2003; Muselli et al., 2009; Zhang et al., 2015). The intensity of water condensation on soil surface is described by Stephan's theory of diffusion, the formal notation of which is expressed by the relation (Brouwers, 1992; Frank-Kamenetskii, 1955):

$$
Q_{v}=\frac{p D N_{u}}{R_{p} T_{p g} L} \ln \frac{p-p_{s}}{p-p_{i}},
$$

where: $Q_{v}$ - amount of condensing vapour per unit of area $\left(\mathrm{kg} \mathrm{s}^{-1} \mathrm{~m}^{-2}\right), p$ - atmospheric pressure $(\mathrm{Pa}), N_{u}$ - Nusselt number (-), $R_{p}$ - individual gas constant of water vapour $\left(\mathrm{J} \mathrm{kg}^{-1} \mathrm{~K}^{-1}\right), T_{p g}$ - temperature at soil surface $\left({ }^{\circ} \mathrm{C}\right), L$ - linear value $(\mathrm{m}), p_{s}-$ saturated vapour pressure for soil surface temperature $(\mathrm{Pa}), p_{i}$ - partial pressure of air vapour $(\mathrm{Pa})$, $D$ - diffusion coefficient $\left(\mathrm{m}^{2} \mathrm{~s}^{-1}\right)$.

Formula (1) includes the Nusselt number which is dependent on the convective heat-transfer coefficient in air $\left(\alpha_{p}\right)$ and the thermal conductivity coefficient in air $\left(\lambda_{p}\right)$ (Jacobs et al., 1996). In consequence, the physical properties of the atmosphere, similarly to its state, affect the 


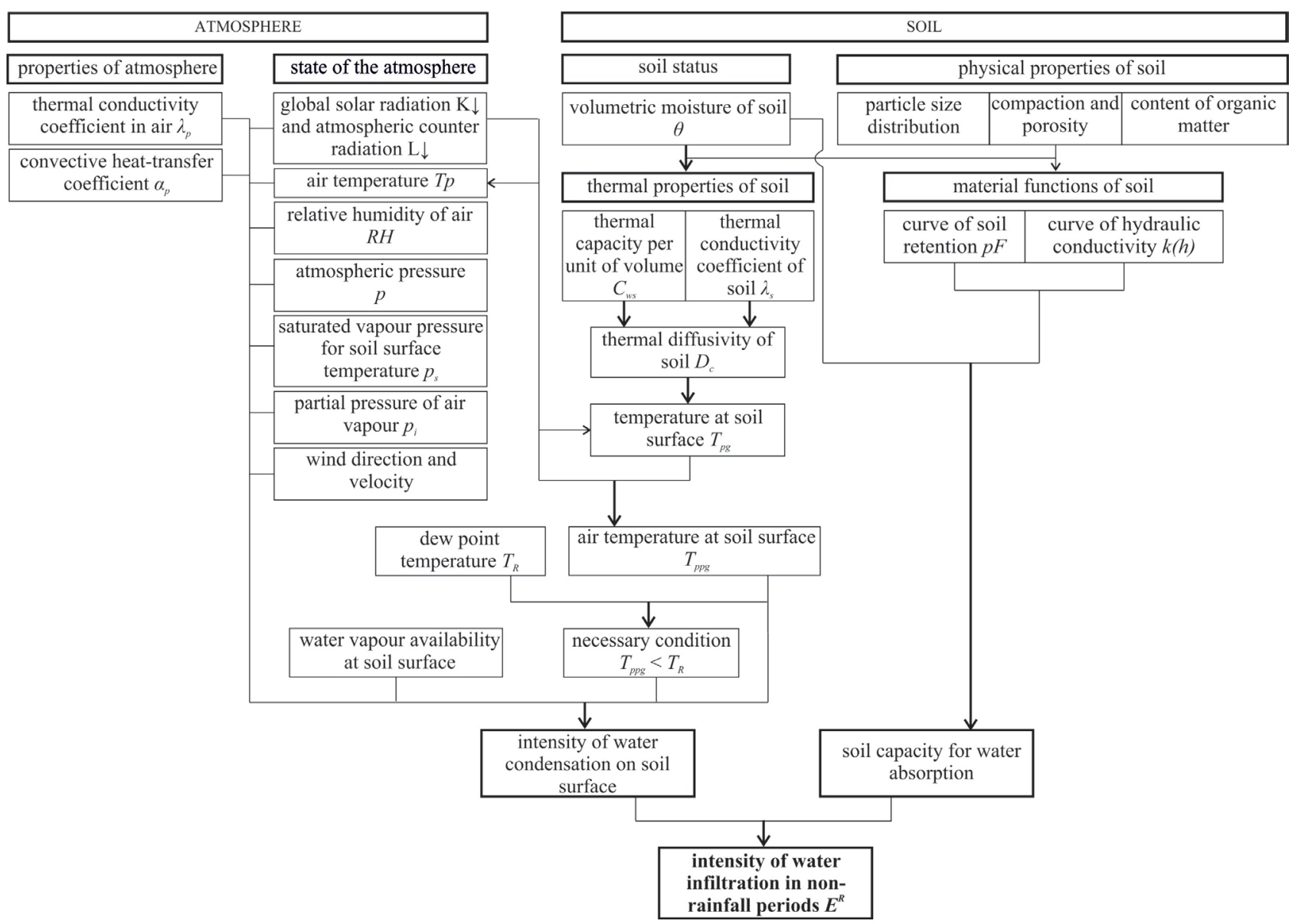

Fig. 1. Factors affecting the intensity of atmospheric water infiltration in non-rainfall periods.

intensity of water condensation on soil surface. The source of meteorological data can be, e.g. the GNSS satellite systems (The Global Navigation Satellite System) (Dymarska et al., 2017). The necessary condition for the appearance of condensed water is that soil surface boundary air temperature $\left(T_{p p g}\right)$ is lower than the dew point temperature $\left(T_{R}\right)$ (Monteith and Unsworth, 2003). Basically, this is possible only when soil surface temperature $\left(T_{p g}\right)$ is lower than the dew point temperature $\left(T_{R}\right)$. The value of $T_{R}$ depends only on the state of the atmosphere - in particular, on the relative humidity of the air (Alnaser and Barakat, 2000). The value of $T_{p g}$ depends on the state of the atmosphere and on the thermal properties of the soil (Agam et al., 2004; Jacobs et al., 2002; Jia et al., 2014; Yamanaka et al., 2007; Zhang et al., 2009). In turn, the thermal properties of the soil are affected by its physical properties (Usowicz et al., 2006, 2013). The rate of change of soil temperature is directly proportional to the thermal conductivity $\lambda_{s}\left(\mathrm{~J} \mathrm{~m}^{-1} \mathrm{~K}^{-1} \mathrm{~s}^{-1}\right)$ and inversely proportional to the thermal capacity $C_{w s}\left(\mathrm{~J} \mathrm{~m}^{-3}\right.$ $\left.\mathrm{K}^{-1}\right)$. The ratio of coefficient $\lambda_{s}$ to coefficient $C_{w s}$ is called the thermal diffusivity $D_{c}\left(\mathrm{~m}^{2} \mathrm{~s}^{-1}\right)$. It is the principal term of the equation describing the relation between temperature change $\delta T_{g}$ in time $\delta t$ and the distance from the surface $\delta z$. The equation has the form:

$$
\frac{\delta T_{g}}{\delta t}=D_{c} \frac{\delta^{2} T_{g}}{\delta z^{2}},
$$

where: $T_{g}$ - soil temperature dependent on $z\left({ }^{\circ} \mathrm{C}\right), z-$ distance from soil surface (depth) (m), $D_{c}$ - thermal diffusivity $\left(\mathrm{m}^{2} \mathrm{~s}^{-1}\right)$.

The values of $\lambda_{s}$ and $C_{w \mathrm{~s}}$ depend on the volumetric moisture of the soil $(\theta)$, and coefficient $\lambda_{s}$ assumes the maximum value when the current volumetric moisture of soil $\theta$ is equal to full saturation moisture $\theta_{s}$. Of note, the increase of coefficient $\lambda_{s}$ is not linear (Usowicz et al., 2013); however, the relation between thermal capacity $C_{w s}$ and current volumetric moisture of soil in the range from $\theta_{r}$ (residual moisture) to $\theta_{s}$ is linear. Therefore, the coefficient of thermal diffusivity $D_{c}$ attains its maximum for a value of volumetric moisture that is characteristic for a given soil. The above considerations explain the effect of water content on heat flux in soil, and, thus, on meeting the condition of $T_{p p g}<T_{R}$.

What is more, in accordance with the block diagram presented in Fig. 1, the thermal properties of soil are affected, apart from the volumetric moisture, by the soil physical 

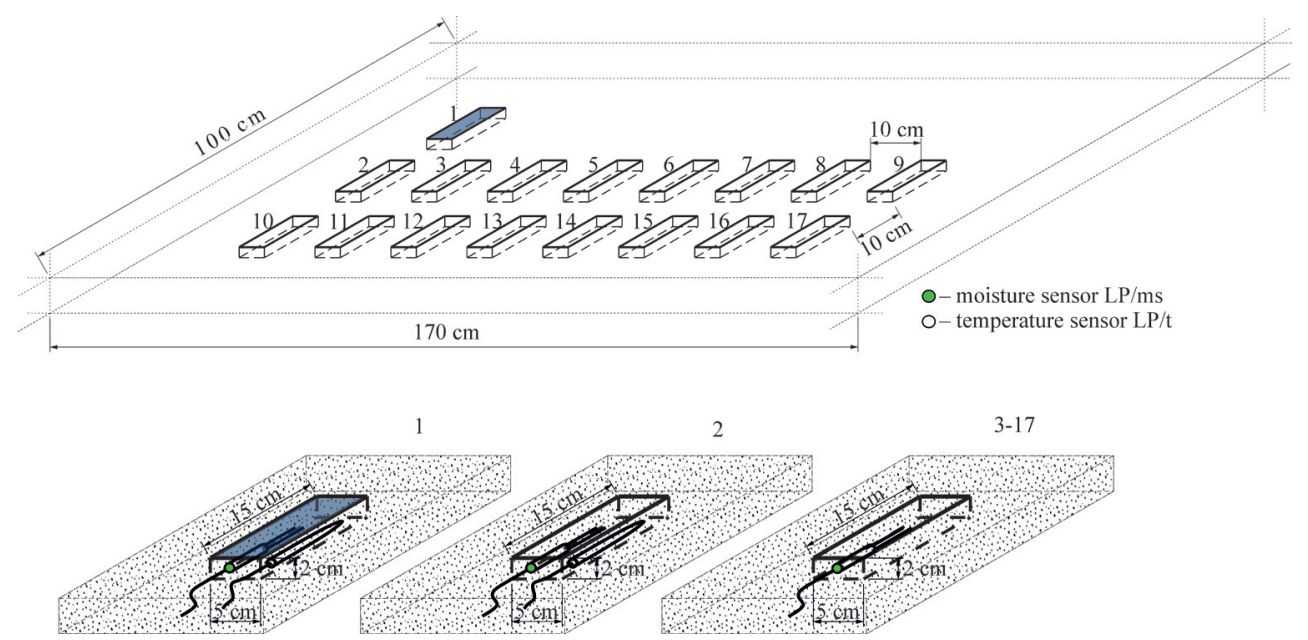

Fig. 2. Schematic diagram of field experiment.

properties (Kaseke et al., 2012b; Li, 2002; Meissner et al., 2010). These include the particle size distribution, the density and the degree of organic matter content. The aforementioned properties determine the material functions of soil, i.e. the water retention curve $(p F)$ and hydraulic conductivity curve $(k(h))$ (Agam and Berliner, 2006; Fischer $e t$ al., 2012; Katata et al., 2007). These functions subsequently determine another key element affecting the intensity of water infiltration, i.e. the soil's ability to absorb water formed on its surface (Jacobs et al., 1999; Katata et al., 2007). From the moment of entering a porous medium, water moves in accordance with the physical field theory, i.e. it moves from a point with a higher total potential, to a point with a lower total potential. In a porous medium (soil), the total potential is the sum of the matric potential and the gravity potential. Therefore, both components have an impact on the rate of water movement in soil in nonrainfall periods. The phenomenon of water infiltration is described by the Richards equation (Lipnikov et al., 2016). Its solution requires the determination of initial and boundary conditions, as well as material functions of the soil.

The intensity of water infiltration in non-rainfall periods is also affected by physiographic factors. These include, e.g. the species and development phase of the vegetative cover (He and Richards, 2015; Ucles et al., 2016; Zhang et al., 2009), the ground slope exposition and the relief (Kidron, 2000; Verhoef et al., 2006). However, these are indirect effects and are omitted in the block diagram presented in Fig. 1.

It needs to be emphasised that the only aspect left out is the effect of the volumetric moisture of soil, and it is the value of $\theta$ that determines both the intensity of water condensation on the soil surface and the ability of the soil to absorb the condensed water. Therefore, the objective of this study was to describe quantitatively the relation illustrating the effect of the current moisture of the surface layer of soil, on the intensity of the process of infiltration in non-rainfall periods.

\section{MATERIALS AND METHODS}

The realisation of the objective formulated in this way requires conducting a number of field experiments. We did these in two stages. Experiment $D_{1}$ (stage 1) in 2013, and experiments $D_{2}$ and $D_{3}$, in 2014 and 2015, respectively (stage 2). The experiments were conducted on the premises of the Observatory of the Faculty of Climatology and Atmosphere Protection, Wrocław University (51 ${ }^{\circ} 06^{\prime} 19,0^{\prime \prime}$ $\mathrm{N} ; 1^{\circ} 05^{\prime} 20,0^{\prime}$ E). In each of the stages, a number of one-day measurement series were conducted. Figure 2 presents a schematic diagram of the experiments, and shows the location of 17 undisturbed soil volumes (monoliths) formed by aluminium barriers. The particle size distribution of mineral parts of the solid phase corresponded to that of sandy loam. In 16 of the spaces (from $i=2$ to $i=17$ ), water flow is possible solely through the top surface, and in space $17(i=1)$ water flow is completely impossible. In the course of the experiments, selected spaces were moistened with various doses of water.

A dew collector was also installed at the experimental site so as to measure the potential condensation efficiency $\left(E^{P}\right)$. This does not depend on a soil's state and properties (Galek et al., 2015). Further on in the paper that parameter is denoted with symbol $E^{P}$. The value of $E^{P}$ can be also measured by means of the porous ceramic plate sensor for atmospheric water deposits measurements (Nakonieczna et al., 2015). The aim of experiment $D_{1}$ was to determine the relation between the value of $E^{R}$ and the volumetric moisture of the soil $\theta_{p g}$ for various values of $E^{P}$. For the first one-day series, precise determination was made of the intensity of infiltration $\left(E^{R}\right)$ for 16 soil volumes with various values of volumetric moisture. In that series, the values of $E^{P}$ were identical for each of the spaces. Only then can the effect of $\theta_{p g}$ on $E^{R}$ be determined correctly. Identical measurement series were conducted on successive days. However, due to varied weather conditions, the values of $E^{P}$ in the successive series were different. 
The values of $E^{R}$ were determined with the use of the knowledge of the dynamics of volumetric moisture of soil in isolated spaces (Janik et al., 2014). The application of the TDR technique and the introduction of temperature correction ensures that soil moisture can be determined with high accuracy (up to $0.001 \mathrm{~m}^{3} \mathrm{~m}^{-3}$ ). The method of determination of the temperature correction is elucidated in the papers by (Janik et al., 2014; Oates et al., 2017; Skierucha, 2009). When the LP/ms probe is placed horizontally, we found that it was possible to register the volume of soil moisture in the top soil layer $(2 \mathrm{~cm})$. The sensitivity zone of the sensor does not exceed beyond the soil monolith determined by aluminum barriers (Janik et al., 2011).

Ultimately, it was possible to construct for successive short time steps (chosen at will) water budget equations for soil volumes 2-17. The only unknown in the equations is the value of $E^{R}$, and on this basis it can be calculated from the formula (Janik et al., 2014):

$$
E^{R}=\left(\left(\theta_{p g, i}\right)^{t^{f}}-\left(\theta_{p g, i}\right)^{t^{i}}\right) h_{i} \Delta t^{-1},
$$

where: $E^{R}$ - intensity of effective non rainfall water flux $\left(\mathrm{mm} \mathrm{day}{ }^{-1}\right), \theta_{p g, i}$ - volumetric moisture in i-th space at the initial moment $\left(t^{i}\right)$, (at the final moment $\left.\left(t^{f}\right)\right)\left(\mathrm{m}^{3} \mathrm{~m}^{-3}\right)$, $h_{i}$ - height of i-th soil volumes (mm), $\Delta t=t^{f}-t^{i}$.

As the time step is short and the moisture is determined accurately, the calculation of the $E^{R}$ value from relation 3 will be precise. The series of experiments within stage one $\left(D_{1}\right)$ were conducted in the period from the 1st of July until the 30th of August, 2013. Soil volume No. 1 was equipped with moisture $(\mathrm{LP} / \mathrm{ms})$ and temperature $(\mathrm{LP} / \mathrm{T})$ gauges. Within that space, potential changes in the readouts of volumetric moisture taken with the TDR apparatus result solely from the diurnal changes of temperature at which the measurements were taken. The temperature correction obtained on this basis will be used for the correction of moisture readings in the other soil volumes (from $i=2$ to $i=17)$. All of them are equipped with a gauge (LP/ $\mathrm{ms}$ ), and soil volumes No. 2 additionally with a temperature gauge $(\mathrm{LP} / \mathrm{T})$. The cause of moisture increase during the non-rainfall periods in the tested soil volumes is the infiltration of water formed on the surface as a result of condensation. The diurnal values of $E^{P}$ were obtained on the basis of data from the dew collector. The experimental data and calculations allowed us to acquire information on the actual intensity of water infiltration to soil $\left(E^{R}\right)$ for soil moisture range from $0.12 \mathrm{~m}^{3} \mathrm{~m}^{-3}$ to $0.32 \mathrm{~m}^{3} \mathrm{~m}^{-3}$ and for the various values of $E^{P}$ which varied in the range from 0.027 to $0.220 \mathrm{~mm} \mathrm{day}^{-1}$. The data set of $\theta_{p g, i}, E^{P}$ and $E^{R}$ will allow us to construct the relation of $E^{R}$ as a function of current moisture of surface soil horizon $\theta_{p g, i}$ and to obtain the value $E^{P},\left(E^{R, f}=f\left(\theta_{p g, i} E^{P}\right)\right)$.

In our study, various classes of function $f$ were analysed, and the approximation was conducted via the method of least squares analysis. The aim of further study was to ve- rify the correctness of the developed function on the basis of independent material. In subsequent years, two experiments were conducted that were identical to that in stage 1 : experiment $D_{2}$ in the period from 31 st October, 2010 to 14th November, 2014, and experiment $D_{3}$ in the period from 4th August to 2nd September, 2015. The adopted measure of goodness of fit of function $f$ was the mean modulus of differences, calculated from the formula:

$$
B_{D_{2},\left(D_{\mathrm{s}}\right)}=\frac{1}{n} \sum_{i=1}^{n}\left|E^{R}\left(\theta_{p g, i}^{D_{2},\left(D_{\mathrm{s}}\right)}, E^{P}\right)-E^{R, f}\left(\theta_{p g, i}^{D_{2},\left(D_{s}\right)}, E^{P}\right)\right|,
$$

where: $B_{\left(D_{2}\right)\left(D_{3}\right)}-$ mean modulus of differences for experiments $D_{2},\left(D_{3}\right)\left(\mathrm{m}^{3} \mathrm{~m}^{-3}\right), n$ - number of compared pairs, $E^{R}\left(\theta_{p g, i}^{D_{2},\left(D_{3}\right)}, E^{P}\right)$-infiltration intensity calculated on the basis of Eq. (3) and data from experiments $D_{2},\left(D_{3}\right)\left(\mathrm{mm} \mathrm{day}^{-1}\right)$, $E^{R, f}\left(\theta_{p g, i}^{D_{2},\left(D_{3}\right)}, E^{P}\right)$ - infiltration intensity obtained on the basis of calculations from function $f\left(\mathrm{~mm} \mathrm{day}^{-1}\right)$ and the mean relative error:

$$
W_{D_{2},\left(D_{3}\right)}=\frac{1}{n} \sum_{i=1}^{n}\left|\frac{E^{R}\left(\theta_{p g, i}^{D_{2},\left(D_{3}\right)}, E^{P}\right)-E^{R, f}\left(\theta_{p g, i}^{D_{2},\left(D_{3}\right)}, E^{P}\right)}{E^{R}\left(\theta_{p g, i}^{D_{2},\left(D_{3}\right)}, E^{P}\right)}\right|,
$$

where: $W_{D_{2},\left(D_{3}\right)}-$ mean relative error (-), other symbols as in Eq. (4).

\section{RESULTS}

Figure 3 presents the values of volumetric moisture during experiment $D_{1}$ in selected soil volumes (numbers 2, 5, $8,11,14,17)$. These are values corrected for temperature. The times of soil moistening that were performed at various doses for each of the soil volumes are illustrated with triangular markers. The lowest value of $\theta_{p g, i}^{D_{1}}$ was obtained in soil volume No. 5 (no moistening) where it amounted to $\theta_{p g, 5}^{D_{1}}=0.12 \mathrm{~m}^{3} \mathrm{~m}^{-3}$. The highest value of $\theta_{p g, i}^{D_{1}}$ was obtained for soil volume No. 17 where it reached $\theta_{p g, 17}^{D_{1}}=0.32 \mathrm{~m}^{3} \mathrm{~m}^{-3}$. The run of the mean diurnal soil temperature $T_{g, \text { mean }}$, which varied in the range from 17 to $33^{\circ} \mathrm{C}$, is also presented. Figure 3 also shows the dates of occurrence of precipitation (P) and their diurnal doses. This allowed the elimination of the periods in which the values of $E^{R}$ cannot be calculated with the method proposed in the paper (Eq. (3)).

Upon analysing the dynamics of soil moisture, one can observe that in non-rainfall periods, and also when the soil was not moistened, an increase of volumetric soil moisture took place. This indicates that water is being infiltrated from the atmosphere. The information presented in Fig. 4 justifies the need for the application of the temperature correction. The figure illustrates the detailed run of changes of volumetric moisture in soil volume No. 17 (experiment $D_{1}$ ) for two selected days (14th and 15th of August). The green line represents data without temperature correction, while the red line represents that with the temperature correction. The differences are not large. For example, on the 15th of 


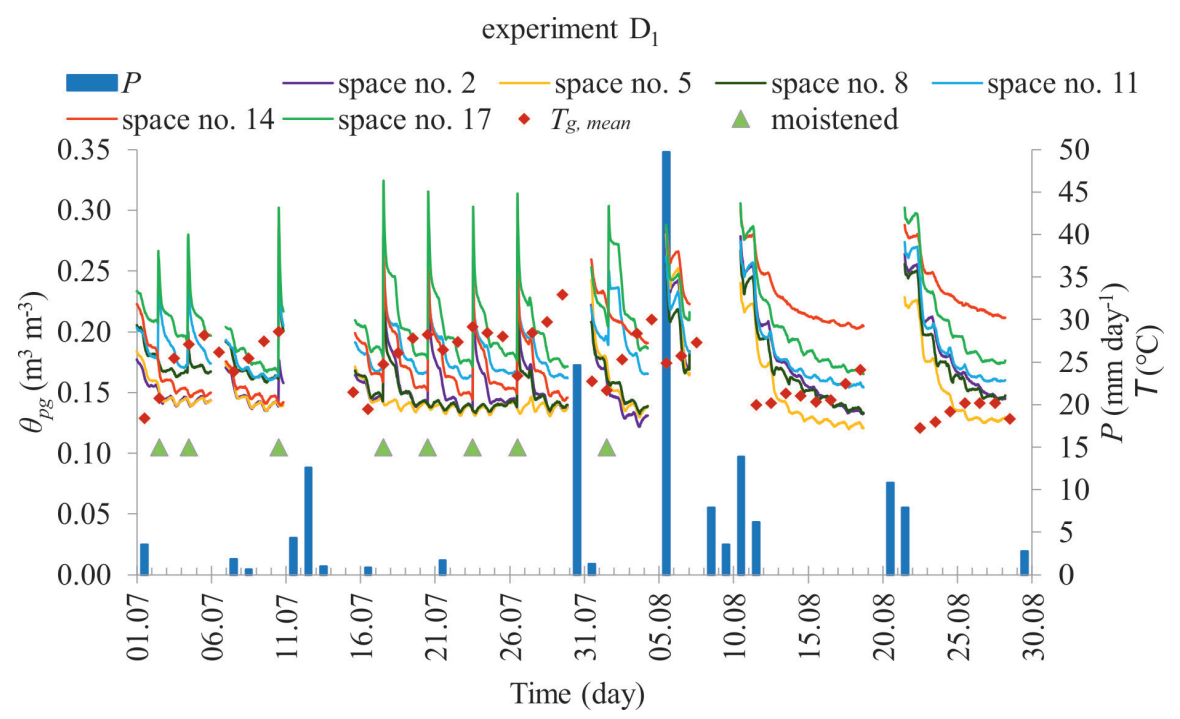

Fig. 3. Soil and atmosphere conditions during experiment $D_{1} ; P$ - precipitations $\left(\mathrm{mm}\right.$ day $\left.^{-1}\right), \theta_{p g}$ - volumetric moisture of soil at the surface $\left(\mathrm{m}^{3} \mathrm{~m}^{-3}\right)$.

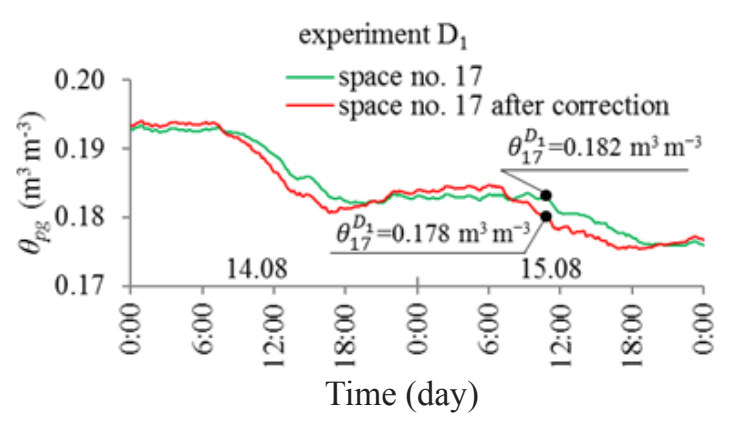

Fig. 4. Dynamics of soil moisture in space No. 17 on 14 th and 15 th of August; $\theta_{p g}-$ volumetric moisture of soil at the surface $\left(\mathrm{m}^{3} \mathrm{~m}^{-3}\right)$.

August at 11:30 the volumetric moisture read directly from the TDR apparatus, $\theta_{p g, 17}^{D_{1, T D R}}$, and the moisture calculated with the temperature correction taken into account, $\theta_{p g, 17}^{D_{1, T R R}}$, differ by as little as $0.004 \mathrm{~m}^{3} \mathrm{~m}^{-3}\left(0.182-0.178 \mathrm{~m}^{3} \mathrm{~m}^{-3}\right)$, i.e. by $2 \%$. However, such a small correction results in a difference in the calculation of the value of $E^{R}$ from Eq. (3) of as much as $65 \%$. On that day, the value of $E^{R}$ without the temperature correction is $0.017 \mathrm{~mm} \mathrm{day}^{-1}$, while after the temperature correction the resulting $E^{R}$ is $0.049 \mathrm{~mm} \mathrm{day}^{-1}$ $((0.049-0.017) / 0.049100=65 \%)$. Therefore, in the case of calculations of this type, the application of temperature correction is necessary (Janik et al., 2014; Skierucha, 2005). During experiment $D_{1}$, the value of $E^{P}$ varied on individual days because the atmospheric conditions were different. However, for a specific day, the values of $E^{P}$ were identical for each soil volume. As the soil volumes have different volumetric moisture at the moment of start of water condensation upon the soil surface, a relation illustrating the effect of this on the value of $E^{R}$ can be constructed. Figure 5 presents such relations for four selected series as drawn from experiment $D_{1}$. The measurement series selected were such that had varied diurnal values of $E^{P}$. For example, on the 1 st of July, the value of $E^{P}$ was only $0.027 \mathrm{~mm} \mathrm{day}^{-1}$, on the 4th of August $-0.076 \mathrm{~mm} \mathrm{day}^{-1}$, and on the 17 th and 19th of July -0.128 and $0.160 \mathrm{~mm} \mathrm{day}^{-1}$, respectively. When $E^{P} \approx 0$, the value of $E^{R}$ is constant and equals $0 \mathrm{~mm}$ day $^{-1}$. When $E^{P}>0$, with the increase of $\theta_{p g, i}$ there is a decrease in the diurnal values of $E^{R}$. In every case, for $\theta_{p g}$ $>0.15 \mathrm{~m}^{3} \mathrm{~m}^{-3}$, the values of $E^{R}$ equal approximately $0 \mathrm{~mm}$ day $^{-1}$. Another regularity that follows from the information presented in Fig. 5 is that with the increase of $E^{P}$, there is an increase in the maximum values $E_{\max }^{R}$. For example, when $E^{P}=0.076 \mathrm{~mm} \mathrm{day}^{-1}$, the value of $E_{\max }^{R}=0.128 \mathrm{~mm} \mathrm{day}^{-1}$, and when $E^{P}=0.160 \mathrm{~mm}$ day $^{-1}-E_{\max }^{R}=0.183 \mathrm{~mm} \mathrm{day}^{-1}$. These observations are indicative of the correctness of the experiment and calculations. The next step was an analysis of the suitability of various classes of functions approximating the value of $E^{R}$ in relation to variables $\theta_{p g, i}$ and $E^{P}$. As a result, the empirical data were approximated with a modified logistic function (Janik et al., 2015). A function of this class, with the applied modification, correctly describes the relations in which values increase with the increase of the first argument and decrease with the increase of the second argument. In addition, the values achieve a state of saturation. The domains are, therefore, the current volumetric moisture of soil $\left(\theta_{p g, i}^{D_{1}}\right)$ and the current value of $E^{P}$. The function has the form:

$$
E^{R, f}\left(\theta_{p g, i}^{D_{1}}, E^{P}\right)=\frac{A}{1+B e^{-C\left(\left(\theta_{p g, i}^{D_{1}, \max }-\theta_{p g, i}^{D_{1}}\right) E^{P}\right)}}
$$

where: $E^{R, f}\left(\theta_{p g, i}^{D_{1}}, E^{P}\right)$ - approximated function of actual water infiltration to soil in non-rainfall periods ( $\left.\mathrm{mm} \mathrm{day}^{-1}\right)$, $\theta_{p g, i}^{D_{1}}-$ current volumetric moisture of surface horizon of soil in experiment $D_{1}\left(\mathrm{~m}^{3} \mathrm{~m}^{-3}\right), E^{P}$ - potential condensation 

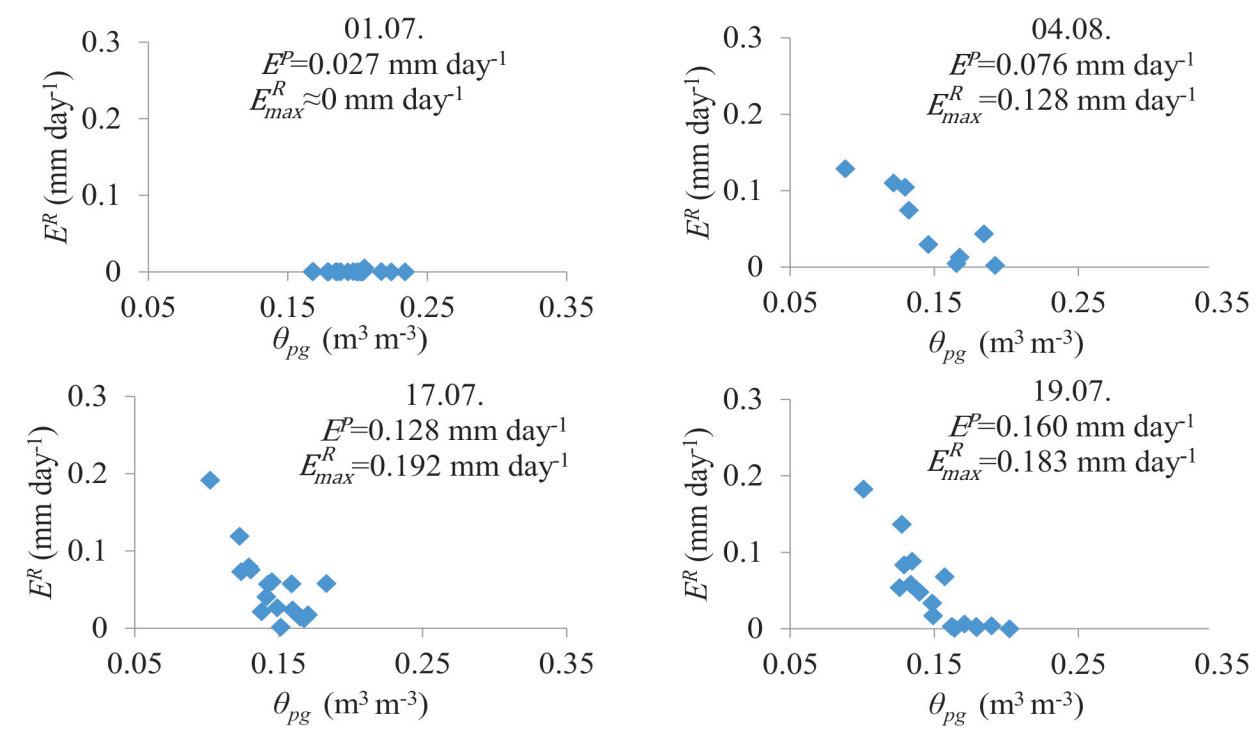

Fig. 5. Relation of actual infiltration $\left(E^{R}\right)$ and moisture $\theta_{p g}$ for various values of $E^{P}$.

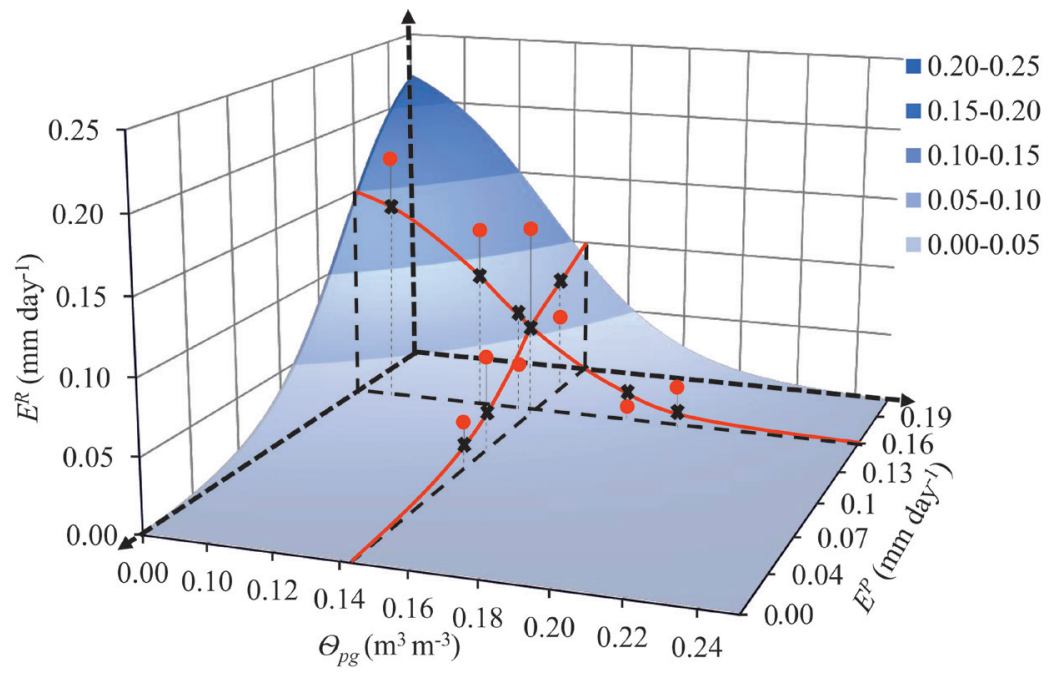

Fig. 6. Shape of function $E^{R, f}\left(\theta_{p g, i,}^{D_{1}}, E^{P}\right)$ describing the dependency of infiltration intensity for sandy loam from volumetric moisture of soil and the potential efficiency of condensation.

efficiency measured on dew collector $\left(\mathrm{mm} \mathrm{day}^{-1}\right), A(\mathrm{~mm}$ $\left.\mathrm{h}^{-1}\right), B(-), C\left(\mathrm{~mm} \mathrm{day}^{-1}\right)-$ empirical coefficients, $\theta_{p g, i}^{D_{1, \max }}-$ maximum volumetric moisture of surface horizon of soil during experiment $D_{1}$ in i-th soil volume $\left(\mathrm{m}^{3} \mathrm{~m}^{-3}\right), \theta_{p g, i}^{D_{1}}-$ volumetric moisture in the surface layer during experiment $D_{1}$ in i-th soil volume $\left(\mathrm{m}^{3} \mathrm{~m}^{-3}\right)$.

Values of parameters $A, B$ and $C$ were chosen so that the sum of squared differences $\left(R^{2}\right)$ of the values of $E^{R}$ obtained on the basis of experimental data and from formula 6 was the smallest. The values of $R^{2}$ were calculated from the formula:

$$
R^{2}=\frac{1}{n} \sum_{i=1}^{n}\left(E^{R}\left(\theta_{p g, i}^{D_{1}} E^{P}\right)-E^{R, f}\left(\theta_{p g, i}^{D_{1}} E^{P}\right)\right)^{2}
$$

where: $R^{2}$ - mean squared difference between values of $E^{R}\left(\theta_{p g, i}^{D_{1}}, E^{P}\right)$ and $\left.E^{R, f}\left(\theta_{p g, i}^{D_{1}}, E^{P}\right)(\mathrm{mm} \mathrm{day})^{-1}\right)^{2}$, remaining symbols as in Eqs (4) and (6).

Ultimately, on the basis of data from experiment $D_{1}$ and from the calculations, the developed function $E^{R, f}$ has the form:

$$
E^{R, f}\left(\theta_{p g, i}^{D_{1}}, E^{P}\right)=\frac{0.24}{1+179.28 e^{-206.40\left(\left(\theta_{p g, i}^{D_{1}, \max }-\theta_{p g, i}^{D_{1}}\right) E^{P}\right)}},
$$

where: symbols as in Eqs (6) and (7).

The shape of function $E^{R, f}$ with parameter values of $A=0.24 \mathrm{~mm} \mathrm{~h}^{-1}, B=179.28, C=206.40 \mathrm{~mm}$ day $^{-1}$ is presented in Fig. 6, together with selected values of $E^{R}$ obtained on the basis of measurements. 
The applicability of the developed function for the description of the phenomenon under consideration in the study for other atmospheric conditions and the same soil type was verified on the basis of data acquired from experiments $D_{2}$ and $D_{3}$, (stage 2). For this purpose, measures of goodness of fit of empirical data were calculated for the developed model described by Eqs (4) and (5). For comparison, the values of these measures are also given with relation to experiment $D_{1}$. The values of the mean modulus of differences are $\mathrm{B}_{D_{1}}=0.025 \mathrm{~mm}$ day ${ }^{-1}, \mathrm{~B}_{D_{2}}=0.017 \mathrm{~mm}$ day $^{-1}, \mathrm{~B}_{D_{3}}=0.029 \mathrm{~mm}$ day ${ }^{-1}$, respectively. The values of the measure calculated on the basis of Eq. (5), $W_{D_{1}}, W_{D_{2}}, W_{D_{3}}$, will not be an analysed herein. This is due to the fact that when $E^{R} \rightarrow 0$ then $W_{D_{1}}, W_{D_{2}}, W_{D_{3}}$ tend to $\infty$. A discussion of the results obtained is not possible. This is due to the fact that the studies published so far do not provide a function that would relate the volumetric moisture of the surface layer of soil with the infiltration in non-rainfall periods.

\section{CONCLUSIONS}

1. The developed relation reveals that with an increase of the volumetric moisture of soil, the intensity of water infiltration from atmosphere decreases. For the sandy loam considered in this study, infiltration ceases when volumetric moisture is higher than $0.15 \mathrm{~m}^{3} \mathrm{~m}^{-3}$.

2. The developed function takes into account the effect of atmospheric condition through the introduction of potential condensation efficiency as measured on a dew collector. The function has the form of a modified logistic function.

3. The application of the TDR technique for the determination of water infiltration intensity in non-rainfall periods requires the application of temperature correction to readouts from the measurement apparatus. Under the conditions of this study, the error may be as high as $65 \%$.

Conflict of interest: The Authors declare no conflict of interest.

\section{REFERENCES}

Agam N. and Berliner P.R., 2006. Dew formation and water vapor adsorption in semi-arid environments - A review. J. Arid Environ., 65(4), 572-590.

Agam N., Berliner P.R., Zangvil A., and Ben-Dor E., 2004. Soil water evaporation during the dry season in an arid zone. J. Geophysical Res.-Atmosp., 109(D16).

Alishaev M., 2013. On condensation and precipitation of atmospheric moisture in the surface layer. Russian Meteorol. Hydrol., 38(8), 522-530.

Alnaser W.E. and Barakat A., 2000. Use of condensed water vapour from the atmosphere for irrigation in Bahrain. Applied Energy, 65(1-4), 3-18.

Beysens D., 2006. Dew nucleation and growth. Comptes Rendus Physique, 7(9-10), 1082-1100.

Beysens D., Muselli M., Nikolayev V., Narhe R., and Milimouk I., 2005. Measurement and modelling of dew in island, coastal and alpine areas. Atmospheric Res., 73(1-2), 1-22.
Brouwers H.J.H., 1992. A film model for heat and mass-transfer with fog formation. Chem. Eng. Sci., 47(12), 3023-3036.

Bryś K., 2013. Dynamics of net radiation balance of grass surface and bare soil (in Polish). Wrocław University of Environmental and Life Science, Monographs, 162, 1-288.

Cassity-Duffey K. and Cabrera M., 2016. Measuring Dew and Its Effect on Ammonia Volatilization from Surface-Applied Broiler Litter in the Southeastern United States. Soil Sci. Soc. Am. J., 80(1), 112-120.

Dymarska N., Rohm W., Sierny J., Kapłon J., Kubik T., Kryza M., Jutarski J., Gierczak J., and Kosierb R., 2017. An assessment of the quality of near-real time GNSS observations as a potential data source for meteorology. Meteorol. Hydrol. Water Manag., 5(1), 3-13.

Fischer T., Veste M., Bens O., and Huttl R.F., 2012. Dew formation on the surface of biological soil crusts in central European sand ecosystems. Biogeosciences, 9(11), 4621-4628.

Frank-Kamenetskii D.A., 1955. Diffusion and Heat Exchange in Chemical Kinetics. Princeton Legacy Library.

Galek G., Sobik M., Blas M., Polkowska Z., Cichala-Kamrowska K., and Walaszek K., 2015. Dew and hoarfrost frequency, formation efficiency and chemistry in Wroclaw, Poland. Atmospheric Res., 151, 120-129.

He S. and Richards K., 2015. The role of dew in the monsoon season assessed via stable isotopes in an alpine meadow in Northern Tibet. Atmospheric Res., 151, 101-109.

Jacobs A.F.G., Heusinkveld B.G., and Berkowicz S.M., 1999. Dew deposition and drying in a desert system: a simple simulation model. J. Arid Environ., 42(3), 211-222.

Jacobs A.F.G., Heusinkveld B.G., and Berkowicz S.M., 2000. Dew measurements along a longitudinal sand dune transect, Negev Desert, Israel. Int. J. Biometeorol., 43(4), 184-190.

Jacobs A.F.G., Heusinkveld B.G., and Berkowicz S.M., 2002. A simple model for potential dewfall in an arid region. Atmospheric Res., 64(1-4), 285-295.

Jacobs A.F.G., Verhoef A., and deBruin H.A.R., 1996. Sensible heat flux from sparse vegetation estimated using nusselt numbers. Physics and Chemistry of the Earth, 21(3), May 1996: Soil-Vegetation-Atmosphere Transfer at Different Scales, 21(3), 107-110.

Jacobson K., van Diepeningen A., Evans S., Fritts R., Gemmel P., Marsho C., Seely M., Wenndt A., Yang X., and Jacobson P., 2015. Non-rainfall moisture activates fungal decomposition of surface litter in the namib sand sea. Plos One, 10(5), $1-22$.

Janik G., Skierucha W., Blas M., Sobik M., Albert M., Dubicki M., and Zawada A., 2014. TDR technique for estimating the intensity of effective non rainfall. Int. Agrophys., 28, 23-37.

Janik G., Szpila M., Słowinska J., Brej G., Turkiewicz M., Skierucha W., and Pastuszka T., 2011. Method for the determination of the sensitivity zone of TDR probe (in Polish). Acta Agrophysica, 18(2), 269-286.

Janik G., Wolski K., Daniel A., Albert M., Skierucha W., Wilczek A., Szyszkowski P., and Walczak A., 2015. TDR technique for estimating the intensity of evapotranspiration of turfgrasses. Scientific World J., 626545-626545.

Jia R.-I., Li X.-r., Liu L.-c., Pan Y.-x., Gao Y.-h., and Wei Y.-p., 2014. Effects of sand burial on dew deposition on moss soil crust in a revegetated area of the Tennger Desert, Northern China. J. Hydrol., 519, 2341-2349. 
Kaseke K.F., Mills A.J., Esler K., Henschel J., Seely M.K., and Brown R., 2012a. Spatial variation of "non-rainfall" water input and the effect of mechanical soil crusts on input and evaporation. Pure Appl. Geophysics, 169(12), 2217-2229.

Kaseke K.F., Mills A.J., Henschel J., Seely M.K., Esler K., and Brown R., 2012b. The effects of desert pavements (gravel mulch) on soil micro-hydrology. Pure Appl. Geophysics, 169(5-6), 873-880.

Katata G., Nagai H., Ueda H., Agam N., and Berliner P.R., 2007. Development of a land surface model including evaporation and adsorption processes in the soil for the land-air exchange in arid regions. J. Hydrometeorol., 8(6), 1307-1324.

Kidron G.J., 2000. Analysis of dew precipitation in three habitats within a small arid drainage basin, Negev Highlands, Israel. Atmospheric Res., 55(3-4), 257-270.

Kidron G.J., Starinsky A., and Yaalon D.H., 2014. Cyanobacteria are confined to dewless habitats within a dew desert: Implications for past and future climate change for lithic microorganisms. J. Hydrol., 519, 3606-3614.

Komori D. and Kim W., 2016. Impact of dew deposition on water flux dynamics at a tropical rainfed paddy field in the dry season. J. Agric. Meteorol., 72(1), 29-36.

Li X.Y., 2002. Effects of gravel and sand mulches on dew deposition in the semiarid region of China. J. Hydrol., 260(1-4), 151-160.

Lipnikov K., Moulton D., and Svyatskiy D., 2016. New preconditioning strategy for Jacobian-free solvers for variably saturated flows with Richards' equation. Advances in Water Resources 94, 11-22.

Malek E., 2003. Microclimate of a desert playa: Evaluation of annual radiation, energy, and water budgets components. Int. J. Climatol., 23(3), 333-345.

Maphangwa K.W., Musil C.F., Raitt L., and Zedda L., 2012. Differential interception and evaporation of fog, dew and water vapour and elemental accumulation by lichens explain their relative abundance in a coastal desert. J. Arid Environ., 82, 71-80.

McHugh T.A., Morrissey E.M., Reed S.C., Hungate B.A., and Schwartz E., 2015. Water from air: an overlooked source of moisture in arid and semiarid regions. Scientific Reports, 5.

Meissner R., Rupp H., Weller U., Vogel H.J., Seyfarth M., Gilkes R.J., and Prakongkep N., 2010. Lysimeter Research in Europe - Technological Developments and Research Strategies.

Monteith J. and Unsworth M., 2013. Principles of environmental physics: plants, animals, and the atmosphere. Academic Press, 401.
Muselli M., Beysens D., Mileta M., and Milimouk I., 2009. Dew and rain water collection in the Dalmatian Coast, Croatia. Atmospheric Res., 92(4), 455-463.

Nakonieczna A., Kafarski M., Wilczek A., Szyplowska A., Janik G., Albert M., and Skierucha W., 2015. Detection of atmospheric water deposits in porous media using the TDR Technique. Sensors, 15(4), 8464-8480.

Oates M.J., Fernandez-Lopez A., Ferrandez-Villena M., and Ruiz-Canales A., 2017. Temperature compensation in a low cost frequency domain (capacitance based) soil moisture sensor. Agric. Water Manag., 183, 86-93.

Skierucha W., 2005. Effect of temperature on soil moisture measurement by reflectometric method (in Polish). Acta Agrophysica, Monographs, 122(5), 1-99.

Skierucha W., 2009. Temperature dependence of time domain reflectometry-measured soil dielectric permittivity. J. Plant Nutrition Soil Sci., 172(2), 186-193.

Tomaszkiewicz M., Abou Najm M., Beysens D., Alameddine I., and El-Fadel M., 2015. Dew as a sustainable non-conventional water resource: a critical review. Environ. Reviews, 23(4), 425-442.

Ucles O., Villagarcia L., Canton Y., and Domingo F., 2016. Partitioning of non rainfall water input regulated by soil cover type. Catena, 139, 265-270.

Usowicz B., Lipiec J., Marczewski W., and Ferrero A., 2006. Thermal conductivity modelling of terrestrial soil media A comparative study. Planetary Space Sci., 54(11), 1086-1095.

Usowicz B., Lipiec J., Usowicz J.B., and Marczewski W., 2013. Effects of aggregate size on soil thermal conductivity: Comparison of measured and model-predicted data. Int. J. Heat Mass Transfer, 57(2), 536-541.

Verhoef A., Diaz-Espejo A., Knight J.R., Villagarcia L., and Fernandez J.E., 2006. Adsorption of water vapor by bare soil in an olive grove in southern Spain. J. Hydrometeorol., 7(5), 1011-1027.

Yamanaka T., Kaihotsu I., Oyunbaatar D., and Ganbold T., 2007. Summertime soil hydrological cycle and surface energy balance on the Mongolian steppe. J. Arid Environ., 69(1), 65-79.

Zhang J., Zhang Y.-m., Downing A., Cheng J.-h., Zhou X.-b., and Zhang B.-c., 2009. The influence of biological soil crusts on dew deposition in Gurbantunggut Desert, Northwestern China. J. Hydrol., 379(3-4), 220-228.

Zhang Q., Wang S., Yang F.-L., Yue P., Yao T., and Wang W.-Y., 2015. Characteristics of dew formation and distribution, and its contribution to the surface water budget in a Semi-arid Region in China. Boundary-Layer Meteorology, 154(2), 317-331. 